Bull Volcanol (1993) 55:147-154

\title{
Deformation of foamed rhyolites under internal and external stresses: an experimental investigation
}

\author{
NSh Bagdassarov, DB Dingwell \\ Bayerisches Geoinstitut, Universität Bayreuth, Postfach 101251, W-8580 Bayreuth, Federal Republic of Germany
}

Received March 6, 1992/Accepted October 30, 1992

\begin{abstract}
The style of magma eruption depends strongly on the character of melt degassing and foaming. Depending on the kinetics of these processes the result can be either explosive or effusive volcanism. In this study the kinetics of foaming due to the internal stresses of gas expansion of two types of obsidian have been investigated in time series experiments $(2 \mathrm{~min}-24 \mathrm{~h})$ followed by quenching the samples. The volumetric gas-melt ratio has been estimated through the density measurements of foamed samples.

The variation of gas volume (per unit or rhyolite melt volume) with time may be described by superposition of two exponentials responsible for gas generation and gas release processes respectively. An observed difference in foaming style in this study is interpreted as the result of variations in initial contents of microlites that serve as bubble nucleation centers during devolatilization of the melts. Quantitatively the values of the gas generation rate constants $\left(k_{g}\right)$ are more than an order of magnitude higher in microlite-rich obsidian than in microlite-free obsidian. Possible origins of differences in the degassing style of natural magmas are discussed in the light of bubble nucleation kinetics in melts during foaming. In a complementary set of experiments the mechanical response of vesicular melt to external shear stress has been determined in a concentric cylinder viscometer. The response of vesicular melt to the pulse of shear deformation depends on the volume fraction of bubbles. The obtained response function can be qualitatively described by a Burgers body model. The experimental shear stress response function for bubble-bearing melt has an overshoot due to the strain-dependent rheology of a twophase liquid with viscously deformable inclusions.
\end{abstract}

Key words: Rhyolite - rheology - vesiculation - bubble growth - shear stresses - foaming - two-phase suspension

\section{Introduction}

The degassing and foaming of rhyolitic magmas due to volatile exsolution is of general interest in volcanology because understanding the physics of these processes can help to elucidate the mechanisms of explosive and effusive eruptions. The question of timing and extent of volatile losses during ascent or eruption of silicic magmas has received much attention in recent years and alternative models of (1) volatile stratification in the magma chamber, (2) volatile escape through permeable foam during ascent, and (3) surface vesiculation during lava flow have been proposed (see Fink et al. 1992 for discussion). Foams (or froth) resulting from exsolution of volatile-bearing melts are two-phase systems consisting of gas-filled bubbles separated by thin liquid films. Twophase suspensions of gas bubbles differ from foams by their significantly smaller ratio of bubble size to the average distance between them (Cheng and Natan 1986). Foams, where the thickness of liquid films is thinner than the individual bubble size, are highly compressible, viscoelastic and possess non-Newtonian rheology depending on the type of deformation. The large scale of foam structure $(10 \mu \mathrm{m}-1 \mathrm{~cm})$ in comparison with the molecular scale of Newtonian fluids results in coupling between the foam structure and the flow and is the main reason for the non-Newtonian rheology of foams (Kraynik 1988). Foams in general can be classified into two types, "polyhedral" and "spherical" according to the shape of the voids. In many vesicular silicate melts (or glassy foams) with $\sim 85-95$ vol.\% porosity, gas bubbles are almost spherical in shape in contrast to the polyhedral foams of some organic liquids. At moderate concentrations of less than 70-75 vol.\%, the bubbles are independent in their relative motion (uncoupled, uncorrelated), and thus the determining factor in foam stability is the mean lifetime of the bubbles (Kappel and Roggendorf 1990). The resistance of such natural foams to collapse can in turn define the style of the degassing process in magmas. Similarly, the way in which natural magmas foam can be a determining factor in the style of silicic volcanism. 


\section{Theoretical background}

The description of melt foaming has several aspects. The first involves the thermodynamics of the equilibrium exsolution of volatiles during depressurization and has been addressed using experimental data on the equilibrium solubility of different volatiles at high pressure (Gerlach 1986). The threshold of magma fragmentation has been evaluated in terms of the critical volumetric ratio of vapor to melt $\left(V_{\mathrm{g}} / V_{1}\right)$ (Sparks 1978). The disruption of vesicular melt into spray under internal stresses due to gas expansion occurs when the gas to melt volumetric ratio is in the range 3-5.

For an exsolution reaction, for example:

$2 \mathrm{OH}_{\mathrm{m}}^{-} \Rightarrow \mathrm{H}_{2} \mathrm{O}_{\mathrm{v}}+\mathrm{O}_{\mathrm{m}}^{2-}$

$\mathrm{H}_{2} \mathrm{O}_{\mathrm{m}} \Rightarrow \mathrm{H}_{2} \mathrm{O}_{\mathrm{v}}$

the diffusion of dissolved species in melt $(\mathrm{m})$ could ratelimit the transfer into the vapor phase $\left(_{v}\right.$ ) (Dingwell and Webb 1990). The exsolution of volatiles in magmas leads to the formation of a separate vapor phase in the form of growing bubbles. If the exsolution process is controlled by diffusion, the bubble growth rate is limited by the characteristic time-scale $\sim R^{2} / D$ (R radius of bubble, $\mathrm{D}$ - diffusion coefficient of volatile component in melt. The pressure inside the bubble $\left(P_{g}\right)$ is determined by the mass balance equation:

$\frac{d\left(\mathrm{P}_{\mathrm{g}} \mathrm{R}^{3}\right)}{d \mathrm{t}} \sim \mathrm{DR}^{2}\left(\frac{\partial C}{\partial \mathrm{r}}\right)_{\mathrm{r}=\mathrm{R}}$

(e.g. Arefmanesh and Advani 1991). Simultaneously, from the balance of forces at the bubble-liquid interface there is deviation of the instantaneous radial stress $\left(\tau_{\mathrm{rr}} \neq 0\right)$ at the bubble boundary from the equilibrium radial stress $\left(\tau_{\mathrm{rr}}=0\right)$ :

$\tau_{\mathrm{rr}}(\mathrm{R})=\mathrm{P}_{\mathrm{g}}-\mathrm{P}_{\infty}-2 \sigma / \mathrm{R}=4 \eta \dot{\mathrm{R}} / \mathrm{R}$

where $\eta$ is viscosity, and $\mathrm{P}_{\mathrm{g}}$ and $\mathrm{P}_{\infty}$ are the gas pressure inside and outside the bubble (valid for non-interacting bubble growth in Newtonian liquid, e.g. Fogler and Goddar 1970). During the process of water diffusion into a bubble, due to the gradient of chemical potential, the viscosity of melt in a boundary layer $\eta$ can increase significantly which can suppress the normal stress relaxation process. The overpressure inside the bubble will thus increase until the tensile strength of the liquid shell separating bubbles can support the normal stresses. Therefore, the degassing process which occurs in melts at low temperature may result in brittle fracturing of the liquid due to unrelaxed stresses on the relatively dry (water-poor) boundary of growing bubbles. This is a potential cause of fragmentation by rupturing of the melt and could contribute to the fragmentation process of some silicic eruptions.

A second aspect of the problem is how the foaming process relates to the rheology of vesicular magmatic suspensions. There is geological evidence that the deformational behavior of obsidian and pumice layers exhibits a pseudoplastic/non-Newtonian rheology (Fink 1984) which stems from the interaction of feldspar mi- crolites or the presence of deformable bubbles. In many geological models, for example, magma rising in a volcanic conduit (e.g. Jaupart and Allegre 1991), lava flowing on the Earth's surface (Jaupart 1991), and dome spacing of pumice (Fink 1980), the presence of bubbles in melt is usually regarded as a factor which leads to viscosity increase because the presence of bubbles disturbs the external shear flow and, thus, the effective viscosity exceeds that of liquid phase (Kraynik 1988). Recent laboratory studies on vesicular melt rheology reveal, however, that at small strains and strain rates and high capillary number $\left(C a=\dot{\varepsilon} \eta \mathrm{R} / \sigma \approx 10^{3}\right)$ increased vesicularity results in a decrease of the shear and volume viscosity of rhyolitic foams (Bagdassarov and Dingwell 1992, 1993) whereas at higher strains and strain rates and capillary number $<1$ the viscosity of bubble-bearing melts increases with bubble content (Stein and Spera 1992). Depending on strains and strain rates foams are expected to have a finite shear modulus like solids due to the surface tension on the boundary of bubbles and to the mechanical interaction between them. Thus, an effective macroscopic model of the mechanical behavior of vesicular melt should include, in addition to a Maxwell viscoelastic element for the liquid phase (Dingwell and Webb 1989), an additional viscoelastic element describing the viscous deformation of bubbles and elastic interaction between bubbles in viscous flow. Due to these extra-viscoelastic elements, foams can respond to different stress tensors qualitatively differently. During foam collapse under compressive or shear deformation, they can possess a strain-(time-) dependent rheology and yield stresses as well. All porous materials in general, and natural foams in particular, are essentially compressible materials. This means that, in addition to a shear viscosity $\eta_{\mathrm{s}}$, foams possess a volume viscosity $\eta_{\mathrm{v}}$ characterizing the process of mechanical energy dissipation due to the compressive deformation.

In the present study, we have performed experiments which address the the role of microlites in obsidian on the kinetics of gas generation and gas release processes (i.e. glass foaming under internal stresses), and the shear stress response of vesicular melts (i.e. foam collapse under external stresses).

\section{Experimental results}

\section{Experiments on foaming}

Obsidians from Little Glass Buttes (Oregon, denoted LGB) and Little Glass Mountain (California, denoted LGM) were chosen for the foaming experiments because they have broadly similar chemistry but different crystal contents. The chemical compositions of LGB and LGM were obtained using a Cameca SX50 miroprobe and are listed in Table 1. The initial water content was determined by the Karl Fischer titration method and is estimated as $\mathrm{H}_{2} \mathrm{O}^{+}=0.17 \pm 0.02 \mathrm{wt} \%, \mathrm{H}_{2} \mathrm{O}^{-} \approx 0.03 \mathrm{wt} \%$ for $\mathrm{LGB}$ and $\mathrm{H}_{2} \mathrm{O}^{+}=0.13 \pm 0.01 \mathrm{wt} \%, \mathrm{H}_{2} \mathrm{O}^{-}<0.01$ wt $\%$ for LGM. The LGM obsidian initially contains $5-$ $10 \mathrm{vol} . \%$ of uniformly distributed microlites regularly 
Table 1. Chemcial composition of rhyolite samples

\begin{tabular}{lcc}
\hline Oxide & LGB & \multicolumn{1}{c}{ LGM } \\
\hline $\mathrm{SiO}_{2}$ & 77.70 & 74.75 \\
$\mathrm{Al}_{2} \mathrm{O}_{3}$ & 13.00 & 13.30 \\
$\mathrm{TiO}_{2}$ & 0.06 & 0.29 \\
$\mathrm{FeO}^{*}$ & 0.71 & 1.86 \\
$\mathrm{MnO}$ & 0.03 & 0.04 \\
$\mathrm{MgO}$ & 0.05 & 0.29 \\
$\mathrm{CaO}$ & 0.53 & 1.21 \\
$\mathrm{Na}_{2} \mathrm{O}$ & 4.06 & 4.51 \\
$\mathrm{~K}_{2} \mathrm{O}$ & 4.18 & 3.86 \\
\hline$\sum$ & 100.32 & 100.11 \\
\hline
\end{tabular}

* $\mathrm{FeO}$ is taken as the sum of ferric and ferrous iron. Cameca microprobe, $15 \mathrm{kV}, 10 \mathrm{nA}, 15 \mathrm{~s}$ count times

In wt $\%$

oriented along the flow direction. They are $\sim 3 \mu \mathrm{m}$ in width and $30-50 \mu \mathrm{m}$ in length. The starting LGB samples were free of microlites.

Cylindrical samples of the starting obsidians $(8 \mathrm{~mm}$ in diameter and $8 \mathrm{~mm}$ in length) were cored from cobbles of LGB and LGM using diamond tools and the ends of the cylinders were ground flat and parallel. The cylindrical surfaces of samples were polished in order to reduce surface roughness that leads to additional heterogeneous bubble generation on the surface of samples. Cylinders of rhyolite were placed on a sheet of platinum foil and annealed isothermally in a $\mathrm{MoSi}_{2}$ element box furnace at temperatures of $1200-1400^{\circ} \mathrm{C}$. The temperature range above the rhyolite liquidus was chosen to provide a reasonable experimental timescale for the generation and collapse of melt foams. The large temperature range $\left(200^{\circ} \mathrm{C}\right)$ gives a basis for the extrapolation to lower (eruptive) temperatures for these melts. The box furnace was preheated to a slightly higher value than the set point temperature of the experiment to compensate for the subsequent decrease of temperature due to the introduction of the sample (Kim and Hrma 1991). The set point temperatures were reached within $1 \mathrm{~min}$. Foaming by devolatilization subsequently began and the samples were eventually quenched by removal from the furnace and cooling in air. The cross sections of quenched vesiculated samples have been analyzed using a Tracor Northern TN-8500 ${ }^{\circledR}$ Image Analysis System combined with an optical microscope. The statistical analysis of bubble sizes has been performed using binary images obtained from the videocamera (Bagdassarov and Dingwell 1992).

Heating of obsidian samples containing water results in intense volatile exsolution. The lifetime or stability of these rhyolite foams was investigated in a time series of quenches $(2 \mathrm{~min}-24 \mathrm{~h})$ following the anneals. The porosities of quenched samples were determined from an Archimedean buoyancy determination and comparison with the density of starting obsidians. The porosity of LGB and LGM samples versus the duration of fusion is shown in Fig. 1. The variation of the gas-volume (per unit of rhyolite melt volume) with time may be described

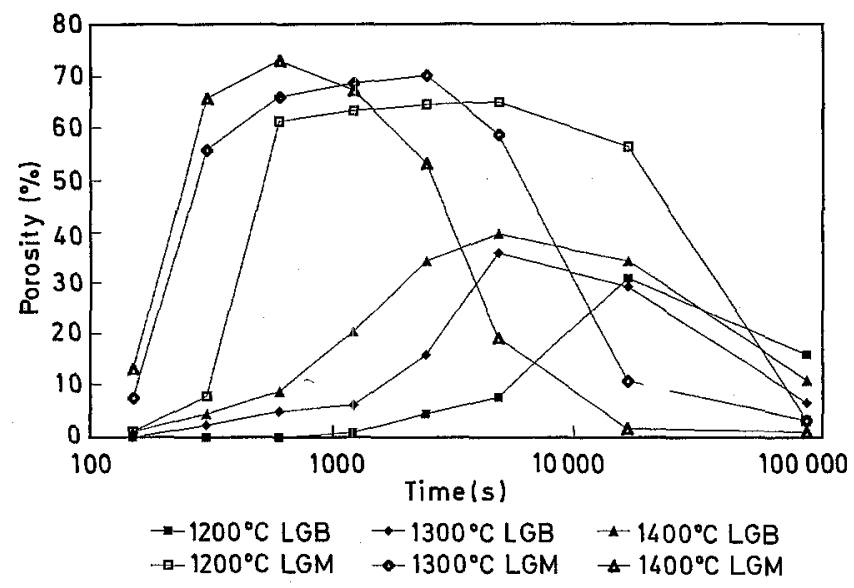

Fig. 1. Kinetics of LGB and LGM obsidians foaming at 1 bar. LGB: solid square, $1200^{\circ} \mathrm{C}$; solid diamond, $1300^{\circ} \mathrm{C}$; open triangle, $1400^{\circ} \mathrm{C}$; LGM: solid square, $1200^{\circ} \mathrm{C}$; open diamond, $1300^{\circ} \mathrm{C}$; open triangle, $1400^{\circ} \mathrm{C}$

by the superposition of two exponentials, one for the gas generation process and one for the gas release process. The equation expressing the gas balance in the sample of finite size is:

$V_{\mathrm{g}} / V_{\mathrm{I}} \sim$ const $\left[\exp \left(-k_{\mathrm{g}} \mathrm{t}\right)-\exp \left(-k_{\mathrm{r}} \mathrm{t}\right)\right]$

where $k_{\mathrm{g}}$ is the gas generation rate constant, $k_{\mathrm{r}}$ is the volume-based gas release rate constant, $V_{\mathrm{g}}$ is the gas phase volume, and $V_{1}$ is the melt volume (Kim and Hrma 1991). This is a semi-empirical relationship but a physical justification of Eq. 4 may be given as follows. In the case of homogeneous nucleation the gas generation rate is determined by the degree of oversaturation in the liquid and the kinetics of gas diffusion from the liquid into the bubble. The degree of oversaturation and diffusion rate decrease with time as long as the concentration of gas in the liquid decreases. In the case of heterogeneous bubble nucleation the rate of gas generation decreases with time because of progressive microlite melting. Assuming that the rate of the oversaturation decrease is proportional to the magnitude of the oversaturation (Walton 1969), an exponential decrease with time of gas generation can be expected (the first exponential in Eq. 4). The rate of bubble release from the melt is inversely proportional to the average bubble residence time at the "surface" of the sample (Kim and Hrma 1991). This time is assumed to depend on the relative volume of bubbles in the melt as $\sim\left(V_{g} / V_{1}\right)^{-1}$ which results in the second exponential in Eq. 4.

The measured porosity ( $\phi$ ) of samples is related to the relative release gas volume through the relationship:

$V_{\mathrm{g}} / V_{1}=\frac{\phi}{1-\phi}$.

The experimental data on porosity of quenched samples have been transformed into relative gas release volume (5) and fitted to Eq. 4. The calculated constants $k_{\mathrm{g}}$, $k_{\mathrm{r}}$ are cited in Table 2 . The gas generation constant $\left(k_{\mathrm{g}}\right)$ depends on the kinetics of volatile exsolution which, in turn, are controlled by the viscosity and volume fraction 
Table 2. Gas generation $\left(k_{\mathrm{g}}\right)$ and gas release $\left(k_{\mathrm{r}}\right)$ rate constants for LGB and LGM obsidians

\begin{tabular}{llllll}
\hline $\begin{array}{l}\text { Temperature, } \\
{ }^{\circ} \mathrm{C}\end{array}$ & \multicolumn{2}{l}{ LGB } & & \multicolumn{2}{l}{ LGM } \\
\cline { 2 - 3 } \cline { 5 - 6 } & $k_{\mathrm{g}}, \mathrm{s}^{-1}$ & $k_{\mathrm{r}}, \mathrm{s}^{-1}$ & & $k_{\mathrm{g}}, \mathrm{s}^{-1}$ & $k_{\mathrm{r}}, \mathrm{s}^{-1}$ \\
\hline 1200 & $3.10^{-5}$ & $1.10^{-5}$ & & $1.10^{-3}$ & $4.10^{-5}$ \\
1300 & $5.10^{-5}$ & $2.10^{-5}$ & & $3.10^{-3}$ & $3.10^{-4}$ \\
1400 & $4.10^{-4}$ & $2.10^{-5}$ & & $4.10^{-3}$ & $3.10^{-4}$ \\
\hline
\end{tabular}

of bubble nucleation. Because the water was originally dissolved in obsidians at pressures greater than $1 \mathrm{bar}$, annealing at this pressure leads to oversaturation in $\mathrm{H}_{2} \mathrm{O}$ which is analogous to the depressurization of uprising magmas. The presence of microlites and other inhomogeneities (cracks, particles, crystals, roughness of a sample surface) promote heterogeneous nucleation of a gas phase. The gas release $\left(k_{\mathrm{r}}\right)$ constant depends on temperature (via viscosity) and the free surface area of melts; it determines how fast the gas phase can escape from the melt via bubble collapse near the free surface of melt, and to some extent, it is influenced by the sample geometry. The difference in the foaming of LGB and LGM obsidians could reflect all but the last factor (see Table 2).
The LGM samples exhibit very rapid nucleation in comparison with LGB samples (the difference in gas generation rate is more than an order of magnitude). In LGM samples bubble nucleation is heterogeneous and fast and, thus, the average distance between bubbles decreases rapidly. The process of bubble nucleation is enhanced by the presence of microlites, the surfaces of which can potentially conserve areas slightly enriched in water (due to water exclusion from growing crystals). The bubble nucleation process in LGB samples is relatively slow: the incubation time for an embryo of critical size is longer than that for the LGM samples.

The analysis of LGM sample cross-sections did not reveal any fracturing of melt, microscopic or macroscopic, around growing bubbles, whereas some samples of LGB clearly exhibited macrofracturing. This might be a result of non-relaxed normal stresses at the growing bubble boundaries. In any case the phenomena of macrofracturing of glassy obsidian samples during the annealing at low temperatures needs more thorough study which will be the subject of further investigations.

The kinetics of bubble growth in LGM obsidian annealed at $1200^{\circ} \mathrm{C}$ is shown in Fig. 2. With time, the mean size of bubbles increases and the smaller size bins progressively disappear from the histogram of size distribution. When distances between growing bubbles become small enough, the process of Ostwald ripening takes place as bigger bubbles grow and coalesce with

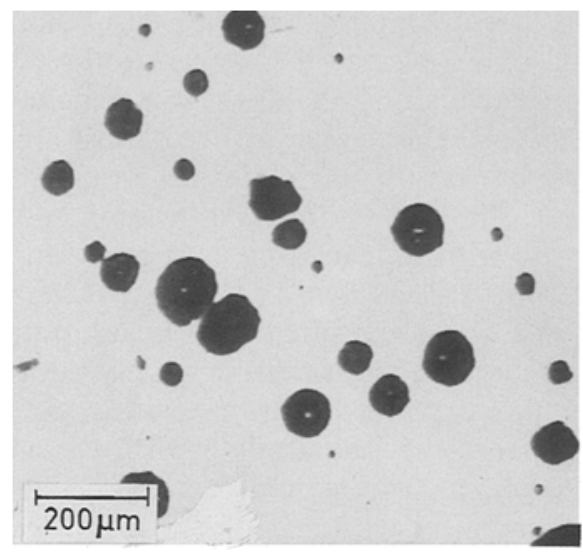

$5 \mathrm{~min}$

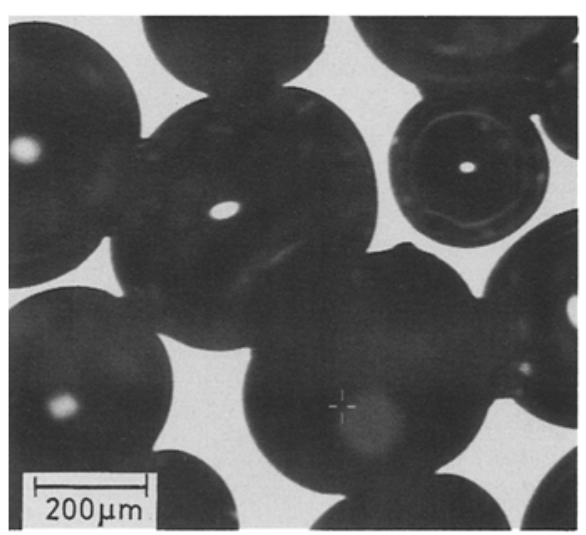

$40 \mathrm{~min}$

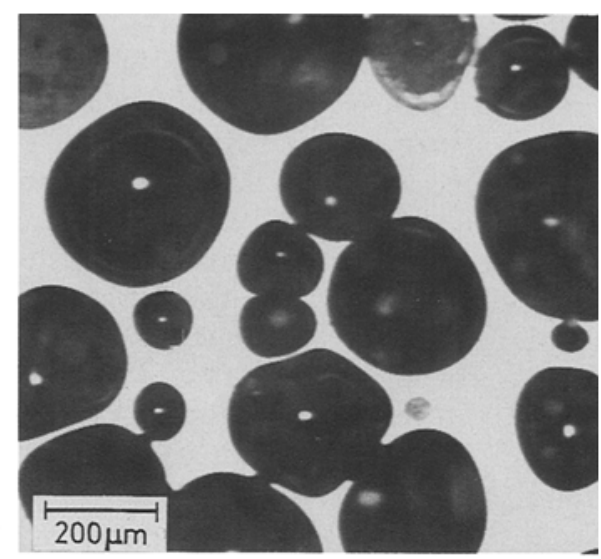

$10 \mathrm{~min}$

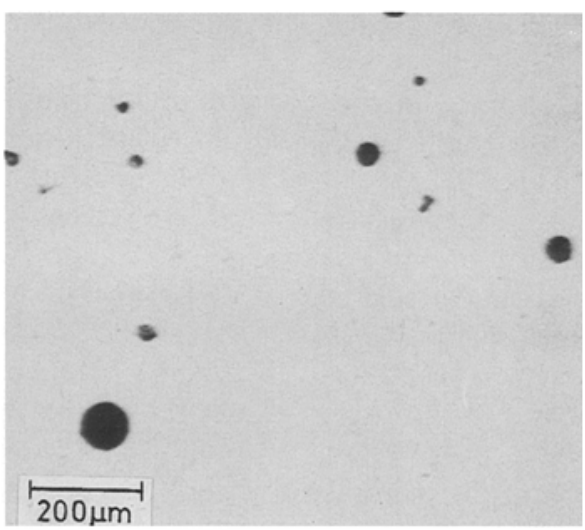

$24 \mathrm{~h}$
Fig. 2. Photos of LGM samples quenched at $1200^{\circ} \mathrm{C}$ vs duration of fusion 
smaller ones. At this stage the mean size of bubbles increases with time as $\mathrm{R} \sim t^{1 / 3}$ (Lifshitz and Pitaevsky 1979). For comparison, the time dependence of bubble size under conditions of thermal growth in a superheated liquid at constant pressure, is $\mathrm{R} \sim t^{1 / 2}$ (e.g. van Wijngaarden and Vossers 1978; Sparks 1978). When bubble growth is limited by diffusion at a constant depressurization rate the bubble size increases with time as $\mathrm{R} \sim t^{2 / 3}$ (Toramaru 1989). The measured mean planar size of bubble distribution in LGM samples quenched from $1200^{\circ} \mathrm{C}$ varies with time as $\mathrm{R} \sim t^{0.6}(t<80 \mathrm{~min})$ indicating some interaction between them during expansion. Later $(t>80 \mathrm{~min})$ when the largest bubbles escape from the sample, the mean size of bubbles decreases with time and only the smallest remain in the melt (Fig. $3)$.

The stability of melt films near the surface of a sample determines the gas release rate $\left(k_{\mathrm{r}}\right)$. The absolute value of $k_{\mathrm{r}}$ also depends on the sample geometry but comparison of $k_{\mathrm{r}}$ obtained on different substances of samples with the same geometry is often used for the characterization of foam stability (e.g. Kappel and Roggendorf 1990; Kim and Hrma 1991). Foams are constantly breaking down due to the drainage of liquid from the inter-bubble space. As a system with a defined surface energy, any foam tends to minimize its surface. The ratio $\sigma / \eta$ is termed the "capillary mobility" (Kappel et al. 1987 ) and determines the velocity of melt drainage. In our experiments with LGM rhyolite melt we observe $k_{\mathrm{r}} \ll k_{\mathrm{g}}$ with the result that the formation of high porosity froth from this type of obsidian is possible. For LGB the difference between $k_{\mathrm{g}}$ and $k_{\mathrm{r}}$ is not as significant, resulting in a moderate porosity of LGB samples under exsolution that in turn exhibits a smaller effective gas release volume. The maximum of $V_{\mathrm{g}} / V_{1}$ ratio during degassing of samples relates to the moment when the coalescence of big bubbles in a foam overwhelms their growth. At this point the foam is effectively permeable. The lifetime of the foam or the resistance of foam to collapse increases with increasing melt viscosity because the drainage of melt from between bubbles slows (Kitchener and Cooper 1959). The lower the temperature, the greater the viscosity of the melt and thus the lifetime of the foam (the residence time of bubbles in the melt) increases.

\section{Rotational viscometry}

The viscoelastic behavior of vesicular LGM rhyolite has been studied in a $\mathrm{MoSi}_{2}$ box furnace equipped with a concentric cylinder viscometer (Dingwell 1989). The viscometer spindle $\left(\mathrm{Pt}_{80} \mathrm{Rh}_{20}\right)$ was used to apply a pulse of stress (torque) to a sample of vesicular LGM. A cylinder of obsidian cored by diamond tool (diameter $24 \mathrm{~mm}$, length $\sim 10 \mathrm{~mm}$ ) from a cobble of LGM was placed in an alumina crucible (inner diameter $25 \mathrm{~mm}$, height $35 \mathrm{~mm}$ ). In the center of each sample there was a drilled hole (diameter $4 \mathrm{~mm}$, length $6 \mathrm{~mm}$ ) prepared to accept the spindle of the viscometer. The sample, with a spindle introduced in the central hole, was heated up to $1250^{\circ} \mathrm{C}$
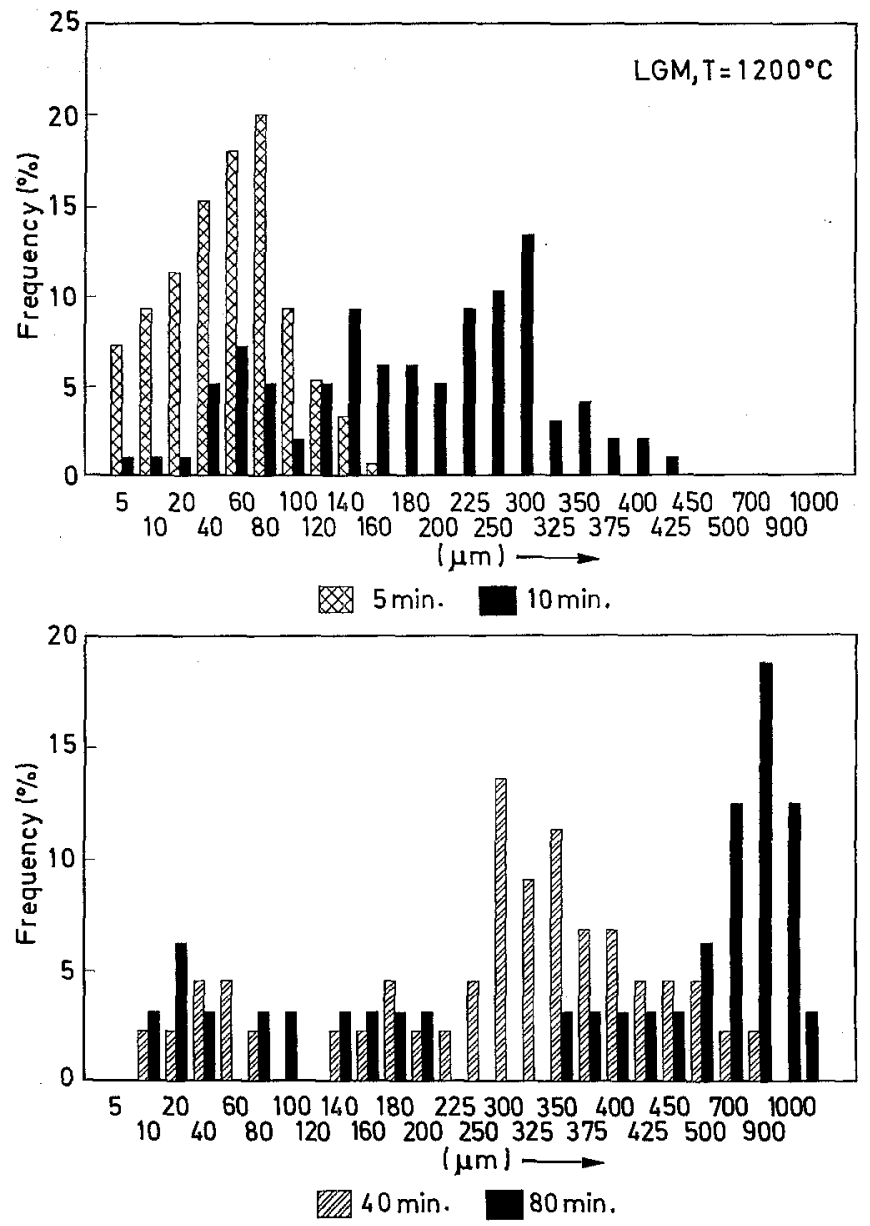

Fig. 3. Distribution function of bubble sizes in LGM samples quenched at $1200^{\circ} \mathrm{C}$ vs duration of fusion

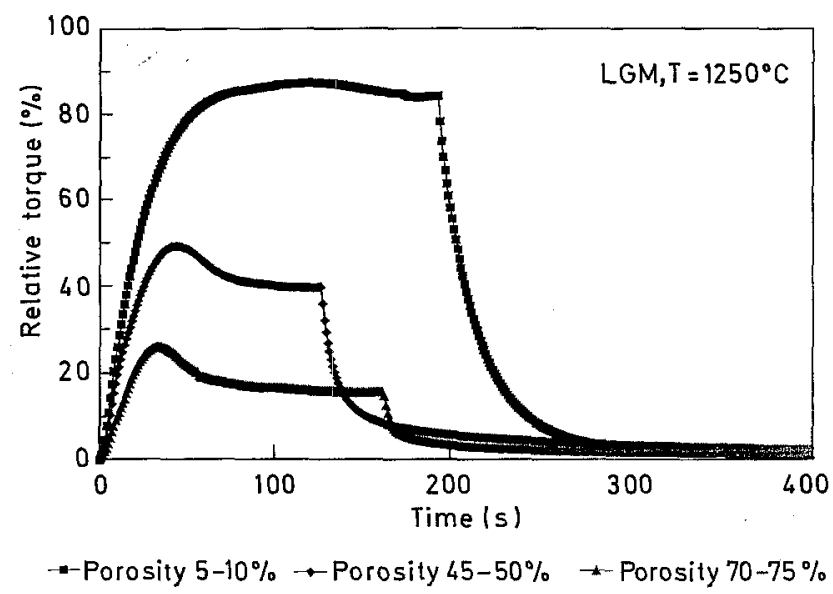

Fig. 4. Shear stress response function in rotational viscometry for LGM foam samples

and held there for $2-3 \mathrm{~h}$. The level of vesicular rhyolite in the crucible as well as the immersed depth of the spindle in the melt were measured using an alumina rod as a dipstick. The spindle was rotated ( $f=0.5$ r.p.m.) in the melted sample for $\sim 150-200 \mathrm{~s}$. The resulting torque was measured with respect to time. The forms of the shear 


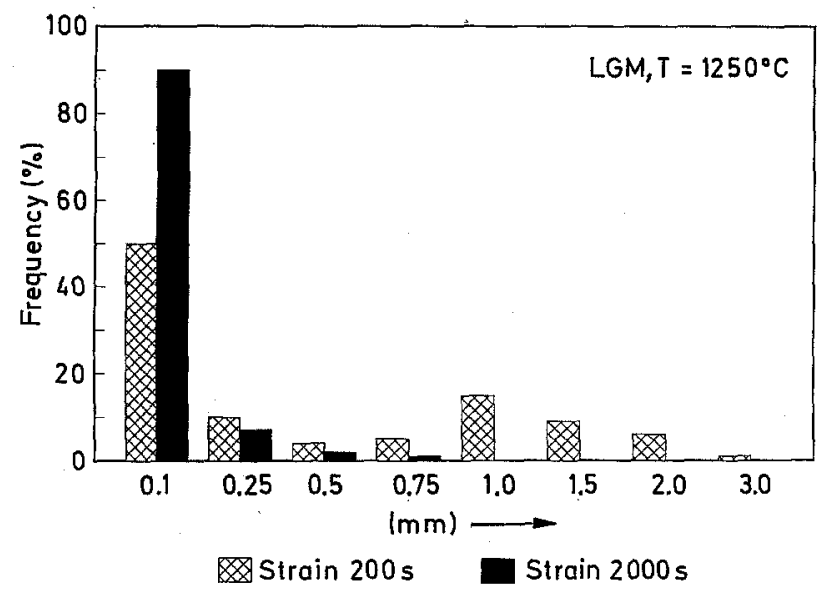

Fig. 5. Size distribution function of bubbles depending on total strain in rotational viscometer

stress response function for samples with different porosities are shown in Fig. 4. The response function for rhyolite samples with $40-75 \%$ porosity exhibits an overshoot on the stress-strain plot. In rhyolite melt with less than 10 vol. $\%$ of bubbles the overshoot is significantly smaller. The appearance of the overshoot can be explained by the deformable geometry of bubbles. After application of an instantaneous shear stress the shapes of the bubbles begin to adopt a new equilibrium geometry. At still higher strains bubbles start to burst and the effective viscosity of the suspension increases (Stein and Spera 1992). In the present experiments the increase of resultant stress has been recorded at strains $>500 \mathrm{~s}$ due to a rod-climbing effect (Weissenberg effect) and bubbles escaping from the batch. Further deformation from spherical to ellipsoidal shape in a shear flow of the suspension results in a non-zero normal stress-difference (Schowalter 1978). The evolution of bubble size distribution during stirring is documented in Fig. 5. After $\sim 200 \mathrm{~s}$ of rotation, melt with $70-75 \mathrm{vol} . \%$ vesicles still represents a foam with close packing of $1-1.5 \mathrm{~mm}$ bubbles and smaller bubbles less than $100 \mu \mathrm{m}$ in the interstitial liquid. After $2000 \mathrm{~s}$ of stirring only small bubbles are retained in the melt. The shear stress response function for this type of melt does not differ from bubblefree rhyolite melts and no overshoot on a stress-strain plot is observed. Thus, the significant reduction of porosity in bubble-bearing rhyolite melt during stirring in a rotational viscometer illustrates clearly a time-dependent viscosity of vesicular shear flow under external stresses.

\section{Discussion}

\section{Degassing and stress relaxation during vesiculation}

Caution must be exercised in the application of gas generation and gas release constants listed in Table 2 directly to magmatic processes. This is due to the potential influence of the thermal inertia of the furnace and of the samples themselves during our experiments. Additionally, the finite sample size influences the gas release proc- ess and thus the kinetics of foam collapse may not correspond precisely to the degassing process in natural magma batches. Nevertheless, the use of precise sample preparation (equal sizes and surfaces) for LGB and LGM obsidians permits a comparison of relative values of $k_{\mathrm{g}}$ and $k_{\mathrm{r}}$ for these two types of obsidians and should help our understanding of the differences that occur under devolatilization of microlite-free and microlite-rich obsidians. The principal challenge here is a quantitative evaluation of the possible volume expansion during depressurization of volatile-bearing melts affected by stress relaxation on bubble boundaries during foaming. The internal stresses occurring in foaming melts will relax faster when the volume viscosity of the vesicular batch is lower. (Inasmuch as the flow around the expanding bubble is dilatational, the righthand side of Eq. 1 is described by the dilatational or volume viscosity of the surrounding suspension.) The volume viscosity of a suspension of gas bubbles is inversely proportional to the volume fraction of voids $(\phi)$ :

$\eta_{\mathrm{v}} \sim \frac{4}{3} \frac{\eta_{\mathrm{s}}(1-\phi)}{\phi}$

(Prud'homme and Bird 1977/1978). With temperature decrease the volume viscosity increases in the same manner as shear viscosity $(\eta)$ (Bagdassarov and Dingwell 1993). Thus, foams of obsidians in which the bubble nucleation process is more intensive (i.e. in which nucleation is heterogenous and $\phi$ is high) are able to relax the stresses without liquid disruption and macrofracturing.

\section{Burgers body model for shear flow of vesicular melt}

The present study on shear stress response of bubblebearing melts has shown a specific overshoot of stresses which is typical for the rheology of two-phase media with changeable geometry of phases. The effective description of a medium with changing geometry of phases under applied stresses can be represented as a Burgers body model (see Appendix) with two characteristic relaxation times.

There are two different timescales in a shear flow of bubble-bearing melt. The first is given by $\tau_{\mathrm{s}}=\eta / \mathrm{G}$, the so-called relaxation time of viscous stresses in melt (Maxwell relaxation time, where $G$ is the unrelaxed shear modulus, see Webb and Dingwell 1990). The second characterizes the way in which vesicles accommodate viscous stresses through deformation (Bentley and Leal 1986). The behavior of deformable vesicles in a time-dependent shear flow is described by the relaxation time $\tau_{\mathrm{b}} \sim \mathrm{R} \eta / \sigma$. For $\mathrm{R} \sim 10 \mu \mathrm{m}, \eta \sim 10^{6} \mathrm{Pas}$, and $\sigma \sim 0.5 \mathrm{~N} / \mathrm{m}$ the relaxation time is $\tau_{\mathrm{b}} \sim 20 \mathrm{~s}$ which is consistent with the observed stress overshoot decay in Fig. 4. The elastic behavior results from the presence of a finite interfacial tension $\sigma$ which acts to oppose viscous deformation of a bubble from the spherical shape (Frankel and Acrivos 1970). The mechanical behavior of bubble-free melts in the temperature range under consideration can be adequately described by the Maxwell body. Viscoelastic behavior of bubbles complicates the model 


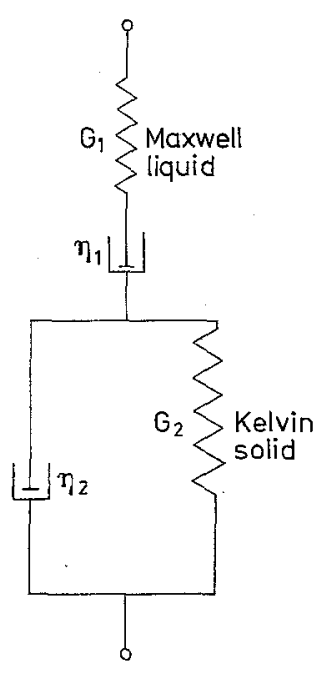

Fig. 6. Schematic illustration of Burgers body model

by adding a pair of elastic and viscous elements (Fig. $6)$.

In the rotational viscometry experiments the response of a material under the action of applied shear rate has been considered. In nature this situation relates more to the sheared contact zones than to the flow of magma in a volcanic conduit under applied pressure. However, inasmuch as the model of mechanical behavior is generally defined, in terms of viscous and elastic elements (Appendix, Eq. 1A), the creep of material under applied stress can be predicted (Appendix, Eq. 2A). The noted time-dependent behavior of natural foams and vesicular melts can contribute to the magma flow at the start of stress application or to the pulsating regime of a gasmagma mixture flowing in a conduit.

The strain- (time-) dependent response of bubblebearing rhyolite melt experimentally noted in this study to some extent can explain the small-scale foliation in the contact zone between obsidian layers and coarsely vesicular pumice described by Fink (1984). Once compressive or shear stresses instantaneously increase in a such layered viscous media with contrasting rheology, they can then decrease with time as long as the shape of vesicles can adopt to new shear stresses. The time-dependent effective resistance of the flow to the applied stresses would result in mechanical instability of the contact between layers which could result in the foliation observed by Fink (1984).

\section{Conclusions}

1. It has been demonstrated experimentally that the initial content of microlites responsible for heterogeneous bubble nucleation is a critical factor of natural foaming kinetics. In natural magma, the process of internal stress relaxation due to bubble growth together with the temperature and dissolved volatile content determine the style of gas exsolution, possible magma dispersion, and, thus, overall eruption.

2. Rotational viscometry experiments have shown that the mechanical response of bubble-bearing melts in shear flow can be described qualitatively using a Burgers body model. External shear stress relaxation in vesicular melts is characterized by two timescales: responsible for the viscoelastic behavior of melt and viscous deformation of void geometry. Deformation of bubble-bearing magma under external stresses changes with the volumetric gas-melt ratio leading to the time-dependent or strain-dependent rheology of vesicular flows.

Acknowledgements. The authors acknowledge financial support from the Alexander von Humboldt Stiftung and the Bayerisches Geoinstitut. The comments provided by J Fink and two anonymous reviewers have improved the manuscript. $J$ Fink and Dr D Johnson kindly supplied samples of LGM and LGB obsidians respectively. H Schulze helped with sample preparation.

\section{Appendix}

A Burgers body model consists of a Maxwell element (Newtonian viscous dashpot with viscosity $\eta_{1}$ and a Hookean elastic spring with rigidity $G_{1}$ in series) and a Kelvin element (dashpot $\eta_{2}+$ elastic spring $\mathrm{G}_{2}$ in parallel) combined in series (Fig. 6). The differential stress-strain equation for a Burgers body ( $\sigma$-stress, $\varepsilon-$ strain) is as follows (e.g. Kornig and Muller 1989):

$\ddot{\sigma}+\left(\frac{\mathrm{G}_{1}+\mathrm{G}_{2}}{\eta_{2}}+\frac{\mathrm{G}_{1}}{\eta_{1}}\right) \dot{\sigma}+\frac{\mathrm{G}_{1} \mathrm{G}_{2}}{\eta_{1} \eta_{2}} \sigma=\mathrm{G}_{1} \ddot{\varepsilon}+\frac{\mathrm{G}_{1} \mathrm{G}_{2}}{\eta_{2}} \dot{\varepsilon}$.

The creep function of this model is given by:

$J(\mathrm{t})=\left(1 / \mathrm{G}_{1}+\mathrm{t} / \eta_{1}+1 / \mathrm{G}_{2}\left[1-\exp \left(\frac{\mathrm{G}_{2} \mathrm{t}}{\eta_{2}}\right)\right]\right)$

There are two relaxation scales in a Burgers body, $\tau_{1}=\eta_{1} / \mathrm{G}_{1}$ and $\tau_{2}=\eta_{2} / \mathrm{G}_{2}$ determining the relaxation process on two elements, the viscoelastic Maxwell liquid and the anelastic Kelvin solid. The frequency-dependent viscosity of a Burgers body is given by:

$\eta(\omega)=\eta_{1} \frac{1+i \omega \tau_{2}}{1-\tau_{1} \tau_{2} \omega^{2}+i \omega\left[\tau_{1}\left(1+G_{1} / G_{2}\right)+\tau_{2}\right]}$

If one assumes that $G_{2} \gg G_{1}$, the real and imaginary components of viscosity are:

$\operatorname{Re} \eta(\omega)=\eta_{1} \frac{1+\tau_{2}^{2} \omega^{2}}{\left[1-\omega^{2} \tau_{1} \tau_{2}\right]^{2}+\left(\tau_{1}+\tau_{2}\right)^{2} \omega^{2}}$

and

$\operatorname{Im} \eta(\omega)=\eta_{1} \frac{\omega \tau_{1}\left(\omega^{2} \tau_{2}^{2}+1\right)}{\left[1-\omega^{2} \tau_{1} \tau_{2}\right]^{2}+\left(\tau_{1}+\tau_{2}\right)^{2} \omega^{2}}$

In the case of $\tau_{2} \Rightarrow 0\left(G_{2} \Rightarrow \infty\right)$ the expressions $(1 A-4 A)$ tend to a creep function and the viscosity of the Maxwell body is given by Debye relaxation functions:

$\sigma(\mathrm{t})=\eta_{1} \dot{\varepsilon}_{0}\left[1-\exp \left(-\mathrm{t} / \tilde{\tau}_{1}\right)\right]$.

The deviation from Maxwell body behavior begins when $\tau_{2} \neq 0$. If $\tau_{2}$ is comparable with $\tau_{1}$ then a time dependence of stresses will be given by:

$\sigma(\mathrm{t})=\eta_{1} \dot{\varepsilon}_{0}+\mathrm{C}_{1} \exp \left(-\mathrm{t} / \tilde{\tau}_{1}\right)+\mathrm{C}_{2} \exp \left(-\mathrm{t} / \tilde{\tau}_{2}\right)$

If $\tilde{\tau}_{1}>\tilde{\tau}_{2}$ and $C_{1}<0, C_{2}>0$ one obtains an overshoot on the stressstrain curve before the stress reaches the steady state value $\eta_{1} \dot{\varepsilon}_{0}$.

\section{References}

Arefmanesh A, Advani SG (1991) Diffusion-induced growth of a gas in a viscoelastic fluid. Rheologica Acta 30:274-283 
Bagdassarov NS, Dingwell DB (1992a) A rheological investigation of vesicular rhyolite. J Volcanol Geotherm Res 50 No 3:307322

Bagdassarov NS, Dingwell DB (1992b) Frequency dependent rheology of vesicular rhyolite. J Geophys Res (in press)

Bentley BJ, Leal LG (1986) An experimental investigation of drop deformation and breakup in steady, two-dimensional linear flows. J Fluid Mech 167:241-283

Cheng HC, Natan TE (1986) Measurements and physical properties of foam. In: Cheremisinoff NP (ed) Encyclopedia of fluid mechanics. Gulf, Houston Vol 3 chapter 1, pp 3-25

Dingwell DB (1989) Effect of fluorine on viscosity of diopside liquid. Am Mineral 74:333-338

Dingwell DB, Webb SL (1989) Structural relaxation in silicate melts and non-Newtonian melt rheology in geological processes. Phys Chem Minerals 16:508-516

Dingwell DB, Webb SL (1990) Relaxation in silicate melts. Eur J Mineral 2:427-449

Fink JH (1980) Gravity instability in the Holocene Big and Little Glass Mountain rhyolitic obsidian flows, Northern California. Tectonophysics 66:147-166

Fink JH (1984) Structural geologic constraints on the rheology of rhyolitic obsidian. J Non-Cryst Sol 67:135-146

Fink JH, Anderson SW, Manley CR (1992) Textural constraints on effusive silicic volcanism: Beyond the permeable foam model. J Geophys Res 97:9073-9083

Fogler HS, Goddar JD (1970) Collapse of spherical cavities in viscoelastic fluids. Phys Fluids 13 No 5:1135-1141

Frankel NA, Acrivos A (1970) The constitutive equation for a dilute emulsion. J Fluid Mech 44 part 1:65-78

Gerlach T (1986) Exsolution of $\mathrm{H}_{2} \mathrm{O}, \mathrm{CO}_{2}$, and $\mathrm{S}$ during eruptive episodes at Kilauea Volcano, Hawaii. J Geophys Res $91: 12177-12185$

Jaupart C (1991) Effect of compressibility on the flow of lava. Bull Volcanol 54:1-9

Jaupart C, Allegre CJ (1991) Gas content, eruption rate and instabilities of eruption regime in silicic volcanoes. Earth Planet Sci Lett 102:413-429

Kappel J, Roggendorf H (1990) Origin, stability, and decay of foam on glass melts. Glastechn Ber $63 \mathrm{~K}: 351-359$
Kappel J, Conradt R, Scholze H (1987) Foaming behavior on glass melts. Glastechn Ber 60 No 6:189-201

Kim D-S, Hrma P (1991) Foaming in glass melts produced by sodium sulfate decomposition under isothermal conditions. J Am Cer Soc 74 No 3:551-555

Kitchener JA, Cooper CF (1959) Current concepts in the theory of foaming. Q Rev Phil Soc London 13:71-97

Kornig M, Muller G (1989) Rheological models and interpretation of postglacial uplift. Geophys J Int $98: 243-253$

Kraynik AM (1988) Foam flows. Ann Rev Fluid Mech 20:325357

Lifshitz EM, Pitaevsky LP (1979) Theoretical physics. Vol 10. Physical kinetics. Nauka Publishing House, Moscow: 515 (in Russian)

Prud'homme RK, Bird RB (1977/1978) The dilatational properties of suspensions of gas bubbles in incompressible Newtonian and non-Newtonian fluids. J Non-Newtonian Fluid Mech $3: 261-279$

Schowalter WR (1978) Mechanics of non-Newtonian fluids. Pergamon Press, Oxford: $300 \mathrm{pp}$

Sparks RSJ (1978) The dynamics of bubble formation and growth in magmas: a review and analysis. J Volcanol Geotherm Res $3: 1-37$

Stein DJ, Spera FJ (1992) Rheology and microstructure of magmatic emulsions: theory and experiments. J Volcanol Geotherm Res 49 No $1 / 2: 157-174$

Toramaru A (1989) Vesiculation process and bubble size distributions in ascending magmas with constant velocities. J Geophys Res $94: 17523-17542$

Walton AG (1969) Nucleation in liquids and solutions. In: Zettlemoyer AC (ed) Nucleation. Marcel Dekker Inc, New York, pp 239-242

Webb SL, Dingwell DB (1990) Non-Newtonian rheology of igneous melts at high stresses and strain rates: experimental results for rhyolite, andesite, basalt and nepheline. J Geophys Res 95:15695-15701

Wijngaarden L van, Vossers G (1978) Mechanics and physics of gas bubbles in liquids: a report on Eurotech 98. J Fluid Mech 87 part $4: 695-704$

Editorial responsibility: H-U. Schmincke 